\title{
Afetividade e motivação na docência online: um estudo de caso
}

\section{Affectivity and motivation in e-learning: a case study}

\author{
Eunice de Castro e Silva \\ Keite Melo da Silva \\ Gilda Helena Bernadino Campos \\ Pontifícia Universidade Católica do Rio de Janeiro (Brazil)
}

\section{Resumo}

Na perspectiva psicogenética walloniana, a afetividade permeia todas as relações entre o aluno-mediador e o objeto do conhecimento. Na Educação a distância será a afetividade que engajará o aluno ao curso e à aprendizagem dos conceitos científicos, por meio da motivação. Esse artigo tem o objetivo de discutir a afetividade construída na mediação pedagógica em um curso online, trazemos o recorte de um estudo de caso sobre o Curso de Especialização em Tecnologias em Educação direcionado para professores e gestores da Educação Básica. Analisamos a relação da afetividade e motivação nas respostas à questão "De que forma a mediação pedagógica do curso contribuiu para o seu desempenho acadêmico". A metodologia utilizada foi a análise de conteúdo, realizada por meio do software Alceste e contou com a devolutiva de 2117 alunos egressos do curso. Os sentidos presentes na categoria motivação foram divididos em dois grupos, sendo o primeiro, a importância do mediador para conclusão do curso, as características ou atribuições do mediador para que possa motivar o aluno, o apoio do mediador para que o aluno concluísse a especialização. Já no segundo grupo, percebeu-se a importância do mediador acompanhar o desempenho do cursista ao longo do curso e as estratégias utilizadas para esse acompanhamento. Concluímos que, as relações de afeto construídas com o mediador vincularam os alunos ao curso, contribuindo para sua permanência e conclusão e que a afetividade tem um peso relevante na garantia do processo de aprendizagem, pois deve estar inserida na mediação pedagógica e na construção do conhecimento.

Palavras-chave: afetividade; docência online; mediador pedagógico; motivação.

\begin{abstract}
In the Wallonian psychogenetic perspective, affectivity pervades all relations between the mediator/ student and the object of knowledge. In distance learning education it seems that affectivity could will engage students in the course, stimulates the learning of scientific concepts through motivation. This article aims to discuss the concept of affectivity built in pedagogical mediation in an on-line course. A case study was built from a Specialization Course about Technologies in Education offered to teachers and managers of Basic Education. We analyzed the relationship between affectivity and motivation through the answers to the question "How
\end{abstract}


did the pedagogical mediation of the course contribute to your academic performance". The methodology used was the content analysis, carried out through the Alceste software and we obtained circa of 2117 answers. The senses in the motivation category were divided into two groups and we stablished some atributes: (a) importance of the mediator for the conclusion of the course, the mediator characteristics to motivate the student, the mediator's support for the student. (b) In the second group, we noticed the importance of the mediator in folowing the student throughout the course and the strategies for this monitoring. In the conclusion we present how the relationship of affection built with the mediator linked the students to the course, contributing to their permanence and sucess in guaranteeing the learning process.

Keywords: affection; distance education; educational mediator; motivation.

A educação a distância é definida pelo decreto n. 5622/2005 como uma "modalidade educacional na qual a mediação didática-pedagógica nos processos de ensino e de aprendizagem ocorre com a utilização de meios e tecnologias de informação e comunicação, com estudantes e professores desenvolvendo atividades educativas em lugares e tempos diversos" (Brasil, 2005). Analisando tal informação podemos inferir que a mediação pedagógica é reconhecida como principal estratégia nos processos de ensino e de aprendizagem da educação a distância (EaD). Nesse sentido, se quisermos garantir o sucesso da aprendizagem na EaD devemos nos atentar para a qualidade da mediação pedagógica que vem sendo oferecida aos discentes dessa modalidade de ensino. Entendemos como mediador pedagógico, aquele profissional que acompanha o aluno, trabalha cotidianamente com ele e participa dos processos de avaliação das aprendizagens (Alonso, 2010). Assim, em conjunto com o docente conteudista, esse docente atua diretamente com o aluno mediando o seu processo de aprendizagem.

Em pesquisa que objetivava mostrar como deve ser a mediação na concepção dos alunos, Silva (2013) mostrou que esta foi compreendida pelos docentes como uma atuação pedagógica dividida em quatro classes ou categorias: estratégia pedagógica de mediação e mediador assistente; mediador tira-dúvidas; motivação ao aluno; formador do mediador pedagógico e influência da mediação na atuação profissional do aluno. A categoria "motivação ao aluno" demostrou que a relação mediador-aluno se estabelece por meio da afetividade, da avaliação e a motivação para a conclusão do curso.

Nesse sentido, este artigo visa apresentar e discutir sobre a afetividade construída na mediação pedagógica de cursos a distância. Para tanto, foi realizado um estudo de caso de um curso de especialização em Tecnologias em Educação direcionado para professores e gestores da Educação Básica de todo território nacional. Para a produção de dados fizemos um recorte das respostas dos cursistas sobre a mediação pedagógica exercida no decorrer do curso, após a aplicação de questionário. Realizouse uma análise de conteúdo de uma questão aberta que foi tratada pelo software Alceste1, em que os resultados serão apresentados posteriormente. 


\section{ALGUNS APONTAMENTOS QUANTO À DÍADE AFETIVIDADE- MOTIVAÇÃO NA EDUCAÇÃO}

Na teoria psicogenética da pessoa completa de Wallon, considera-se a dimensão afetiva como central na constituição do sujeito, e essa teoria vem sendo resgatada em pesquisas recentes (Veras e Ferreira, 2010; Tassoni e Leite, 2013; Ferreira e AciolyRégnier, 2010, Simonetto; Murgo e Ruiz, 2016; Carvalho e Lima, 2015; Andrade, Freire e Neri, 2015; David et al., 2014; Pereira e Almeida, 2016, entre outras) que relacionam a afetividade e aprendizagem de jovens, adultos e seus professores, percebendo o sucesso da aprendizagem por meio da interação e o vínculo afetivo. É um pressuposto que rompe com a superação da fragmentação que imperou na modernidade, buscando a integração, enxergar o homem como ser completo que é.

A cognição em Wallon (Ferreira e Acioly-Régnier, 2010) se assemelha à afetividade por ir se complexificando na interação com o social e quando adulto, o sujeito alcançaria o equilíbrio entre afetividade e cognição, ainda que a instabilidade surja em alguns momentos. A afetividade interfere diretamente na aprendizagem e compreender como se constitui esta relação de interdependência, observando as ações pedagógicas e como professores e alunos estão amadurecidos em relação à educação da emoção, auxilia no entendimento dos fatores que podem levar um aluno a abandonar um curso. Há situações onde o abandono é oriundo de um conflito com seu mediador ou com outro aluno, mas se afetividade se desenvolveu, apesar da existência do conflito, o estímulo recebido pode fazê-lo rever o evento com outra ótica e permanecer no curso.

Para Tardif e Lessard (2014), o trabalho docente é um trabalho interativo, um profissional das relações humanas que ao interagir com os seus alunos, se entrega, se envolve. Essa especificidade da função docente possui por base, as suas próprias emoções e as de seus alunos. Acionar a motivação/desejo/significações dos alunos para adesão a uma proposta de trabalho é vinculá-los afetivamente ao proposto, provocar entusiasmo, acessar suas emoções. Os autores delimitam ainda mais a especificidade desse trabalho interativo, entendendo-o com um trabalho investido: “...um professor não pode, apenas, 'fazer o seu trabalho', mas que deve engajar-se e investir a si mesmo no que é como pessoa nesse trabalho" (Tardif e Lessard, 2014, p. 268). Na interação com os seus alunos, a personalidade do professor se faz presente, incluídas aí as suas qualidades, sensibilidade, defeitos, entre outras características que se vinculam à mediação pedagógica. A seguir, trazemos para nossa discussão, estudos recentes realizados sobre a relação da afetividade e/ou motivação e o seu impacto na aprendizagem.

Réka et al. (2015) em seu estudo de associação entre motivação e sucesso acadêmico na EaD em comparação com a modalidade full-time, concluíram que existe uma relação específica em cada modalidade, entre os componentes motivacionais intrínsecos ou extrínsecos e o desempenho acadêmico. Os autores buscaram identificar o perfil motivacional de 162 estudantes do curso de Psicologia e Ciências 
da Educação da Universidade Babes-Bolyai. Após a análise dos dados contidos nos questionários aplicados, concluíram que os alunos da EaD apresentavam mais motivação intrínseca e quando tinham bom desempenho acadêmico, havia sinais de maior autonomia e competência. Enquanto os alunos da full-time, apresentavam mais sinais da motivação extrínseca e quando tinham bom desempenho, não se traduzia em autonomia e competência. A motivação intrínseca nesse caso estaria relacionada à autorealização e necessidade de ampliação de conhecimentos, enquanto a extrínseca, se dedicaria a evitar sanções e punições devido aos baixos resultados.

No estudo que Goulao (2016) realizou como revisão de literatura, a autora buscou compreender a constituição das relações afetivas, por meio da língua escrita na interface fórum. Nessa interface seria possível se concretizar a comunicação sócio-afetiva que garante

um processo dialógico permitindo aos intervenientes que, a respeito de um determinado tema, possam trocar pontos de vistas, concordar, discordar, entre eles. É este processo que ajuda a formar e a estabelecer vínculos entre os diferentes participantes, pois para existir esta troca de ideias é necessário que todos aprendam a ouvir o outro, a respeitar as diferentes posições o que, por sua vez, possibilita o encontrar de novos sentidos (Goulao, 2016, p. 170).

Reconhecendo que o fórum possui características linguísticas próprias, a presença social pode ser concretizada por meio de mensagens de texto com a participação ativa de alunos e professor, expressando suas perspectivas personalizadas e a identidade objetiva que emerge da emoção-cognição. Ao mediador é esperado que modere as relações interpessoais e intrapessoais, orientando emoções, afetos e atitudes, além de aliar ao processo de hétero-avaliação de conteúdos e desempenho. Também espera-se do mediador que se preocupa com a constituição de relações afetivas, que leve $o$ aluno a acionar suas competências metacognitivas, em caso de necessidade de ajuste das estratégias pedagógicas, que o integre à comunidade de aprendizagem, e estimule-o, evitando assim, a sensação de esforço solitário que acomete alguns alunos da modalidade a distância.

Outras pesquisas vêm investindo nos estudos do uso da tecnologia como agente da motivação. Liew et al. (2016) investiga o impacto da expressão sorridente do agente pedagógico (interface digital com objetivo de se assemelhar a um tutor, para oferecer um caráter mais pessoal ao ambiente virtual do curso) no acesso positivo às emoções, motivação e aprendizagem de um aluno, no ambiente virtual. Tovar e Bercht (2016) se dedicaram a verificar não a afetividade entre sujeitos, mas entre o aluno e o objeto do conhecimento, mediado pelas tecnologias. A tecnologia adotada foi o software GeoGebra para trabalhar a geometria de forma dinâmica, lúdica e interativa. Ao ter contato com essa geometria dinâmica, o aluno acessaria a sua dimensão afetiva, se identificando e experimentando emoções que o motiva a aprender de forma significativa. 
Para analisar essa relação entre a dimensão afetiva, o aluno e o conhecimento matemático, os autores anunciam o conceito "Afecto Cognitivo" que pode ser entendido como o "conjunto de estímulos, emociones y sentimientos que se generan en la relación bidireccional del sujeto (estudiante) y el objeto conocimiento; antes, durante y después del momento de enseñanza aprendizaje" (Tovar, Bercht, 2016, p. 7). Esses vínculos com o objeto do conhecimento, por meio da motivação intrínseca, é um dos principais objetivos docentes em sua mediação. Para isso, a adoção de tecnologias que aproximem os envolvidos, com recursos que otimizem a percepção, comunicação e expressão de sensações, otimizando o pano de fundo para a relação afetiva se constituir, pode garantir o impacto desejado na aprendizagem e desenvolvimento dos alunos.

Quando tratamos da interação entre sujeitos, construindo colaborativamente o conhecimento em um ambiente virtual, onde expressões e tom de voz são mediados pelas tecnologias digitais, mas são compreensíveis e afetam as relações, retomamos a noção de "trabalho investido" de Tardif e Lessard (2014) por compreendemos que a afetividade nesse caso, é uma via de mão dupla. Sobre isso, Bannel et al. (2016), ao analisar a percepção vygotskyana sobre afetos, apresentou essa noção como "a capacidade de afetar e ser afetado, pela qual percepções, sentimentos, funções psicológicas superiores e atividade cerebral unificam-se na atividade das pessoas no mundo" (p. 59).

Veras e Ferreira (2010) analisaram a afetividade na relação entre docentes e alunos no ambiente acadêmico e suas implicações na aprendizagem. Em seus achados, as autoras perceberam que a postura do docente afeta diretamente a aprendizagem do aluno. Nas análises das autoras, mesmo os docentes exigentes, se envolvessem os alunos por meio do diálogo e negociação, obtinha-se avaliação positiva por parte dos alunos. Essa conclusão pode ser confirmada por Wallon, quando o autor relaciona a interação entre os sujeitos às emoções e quando essas se transformam em laços de afetividade. A aprendizagem é viabilizada por meio do vínculo com o mediador que afeta e mobiliza essas emoções.

As situações com as quais a emoção confunde o indivíduo não são apenas incidentes materiais, mas também relações interindividuais. $\mathrm{O}$ ambiente humano infiltrase no meio psíquico e substitui-o em grande parte... Ora compete precisamente às emoções, pela sua orientação psicogenética, desenvolver estes laços, que se antecipam à intenção e ao raciocínio. As consequentes atitudes, os efeitos sonoros e visuais resultantes, representam para as outras pessoas um estímulo do maior interesse, capaz de mobilizar reações semelhantes, complementares ou recíprocas, quer dizer, em relação com a situação de que são efeito e o índice (Wallon, 2007, p. 149).

Por outro lado, os docentes que tiveram avaliação negativa dos alunos eram aqueles que não incentivavam à participação. Os docentes mais implicados tinham retorno dos alunos com participação e envolvimento. Assim, podemos perceber como a afetividade interfere diretamente na aprendizagem, pois engaja os alunos 
na adesão às aulas, às atividades, e os vinculam ao proposto pelo docente. Fica mais evidente a relação entre afetividade e cognição e como estes aspectos se afetam mutuamente.

No trabalho de Simoneto, Murgo e Ruiz (2016), onde os autores analisaram a percepção dos cursistas quanto à afetividade entre professores e alunos, o resultado demonstrou grande valorização da afetividade para aprendizagem e permanência em um curso. Nos resultados do trabalho, apareceram as noções de que o professor precisa levar o aluno a confiar nele, deixando-o seguro e estimulando o respeito recíproco. Nesses achados, as características de um professor afetivo seriam: carinho, paciência, cuidado, dinamismo, atenção, consideração, bom humor, responsabilidade proximidade, afetuosidade, segurança, paciência, compreensão, humildade, empatia, respeitoso, autoconfiança, abertura às críticas e ao diálogo (Simoneto, Murgo e Ruiz, 2016, p. 89). Essas características, quando não contempladas, poderia inclusive levar o aluno a rejeitar o professor ou a disciplina, contribuindo assim, com o desinteresse com o curso.

A partir da análise dos trabalhos acima citados, destacamos as seguintes questões a serem consideradas na mediação pedagógica na EaD para aliar a relação afetiva, motivação e aprendizagem:

- A motivação intrínseca pode se voltar para uma relação positiva e afetiva com o objeto do conhecimento. O professor pode contribuir com estímulos nesse sentido, acionando as emoções que vinculem o aluno ao objeto do conhecimento;

- Em fóruns de discussão é possível reconhecer a manifestação da afetividade por meio de diversos recursos linguísticos. O professor precisa estar atento à possível sensação de isolamento, bem como dificuldade do aluno em reconhecer a sua própria competência metacognitiva sem auxílio;

- A postura do professor pode interferir diretamente na aprendizagem do aluno e essa postura não vincula a rigorosidade docente à interferência negativa, mas seria negativa se não estivesse garantida a abertura ao diálogo e negociações;

- Oferecer um clima de segurança, respeito, rapidez nas respostas, proximidade e até bom humor podem vincular mais e melhor o aluno ao curso;

- A qualidade do vínculo afetivo entre o professor e aluno da EaD pode diminuir a possibilidade de evasão;

- É desejável a adoção de tecnologias que aproximem os sujeitos em um curso na modalidade $\mathrm{EaD}$, com recursos que otimizem a percepção, comunicação e expressão de sensações;

- A forma com que o professor avalia e comunica o seu feedback, com clareza e cuidado na explicação também incorporam manifestações afetivas, inclusive porque a recepção de feedback avaliativo quase sempre despende alguma emoção, então o cuidado na emissão do feedback pode transformar essa emoção em elemento propulsor para avanços na aprendizagem e maior engajamento no curso. 


\section{ASPECTOS METODOLÓGICOS E O CONTEXTO DA PESQUISA}

O contexto da pesquisa foi o Curso de Especialização Tecnologias e Educação, que fez parte do Programa Nacional de Formação Continuada em Tecnologia Educacional (Proinfo Integrado) em parceria com o Departamento de Educação e a Coordenação Central de Educação a Distância da PUC-Rio. Em sua segunda edição, o curso ofereceu 6.030 vagas, das quais 5.852 foram preenchidas por profissionais da Educação Básica, formando um total de 208 turmas.

Ao final do curso, foi realizada uma avaliação institucional com os alunos. De acordo com Campos (2007) a avaliação institucional foi composta de uma avaliação final orientada para cursistas, mediadores pedagógicos e orientadores, e teve como finalidade possibilitar a "fala" desses públicos avaliados. Tais questionários foram divididos em blocos de questões abertas e fechadas abrangendo a temática de mediação pedagógica, usabilidade, design didático, ambiente virtual de aprendizagem, material didático, conteúdos e arquiteturas pedagógicas.

Dentro do bloco de mediação pedagógica analisamos a questão "De que forma a mediação pedagógica do curso contribuiu para o seu desempenho acadêmico". Dos 3828 aprovados no curso, tivemos um retorno de quase $60 \%$ dos questionários, perfazendo esse o nosso corpus de análise.

Realizamos uma análise de conteúdo do corpus de dados com o software Alceste - Análise de Lexemas Coocorrentes. A funcionalidade desse programa consiste em uma análise computadorizada substituindo o sentido da frase e analisando coocorrência localizada de palavras. Dessa forma, o sentido das sentenças pode ser capturado pela identificação de palavras juntas nas frases coocorrendo em um grande número de respondentes. Kroberger e Wagner (2008) consideram o software Alceste uma técnica por ter sido desenvolvido para investigar a distribuição de vocabulários em um texto, e uma metodologia, pelo fato do programa integrar uma grande quantidade de métodos estatísticos sofisticados. Segundo os autores, "tomado em seu conjunto, o programa realiza uma complexa classificação hierárquica descendente, combinando elementos de diferentes métodos estatísticos como segmentação, classificação hierárquica e dicotomização, baseadas em médias recíprocas, ou análise de correspondência" (Kronberger, Wagner, 2008, p. 26).

Em termos práticos, o software Alceste procura operar uma abordagem pragmática do texto, centrada na coocorrência lexical, na copresença do léxico em uma unidade contextual do texto.

\section{DIALOGANDO COM OS RESULTADOS}

O dendograma2 da figura 01 mostra a identificação das classes por meio da Classificação Hierárquica Descendente. Nele podemos identificar dois grupos. O primeiro grupo é formado pela Classe 3 e o segundo grupo é formado pelas classes 2, 4 e 1. Segundo Kronberger e Wagner (2008), a hierarquização das classes demonstra 
análises sucessivas das palavras plenas, que se interrompe se um predeterminado número de repetições não resulta em divisões posteriores.

\section{Figura 1. Classificação Hierárqui1ca Descendente}

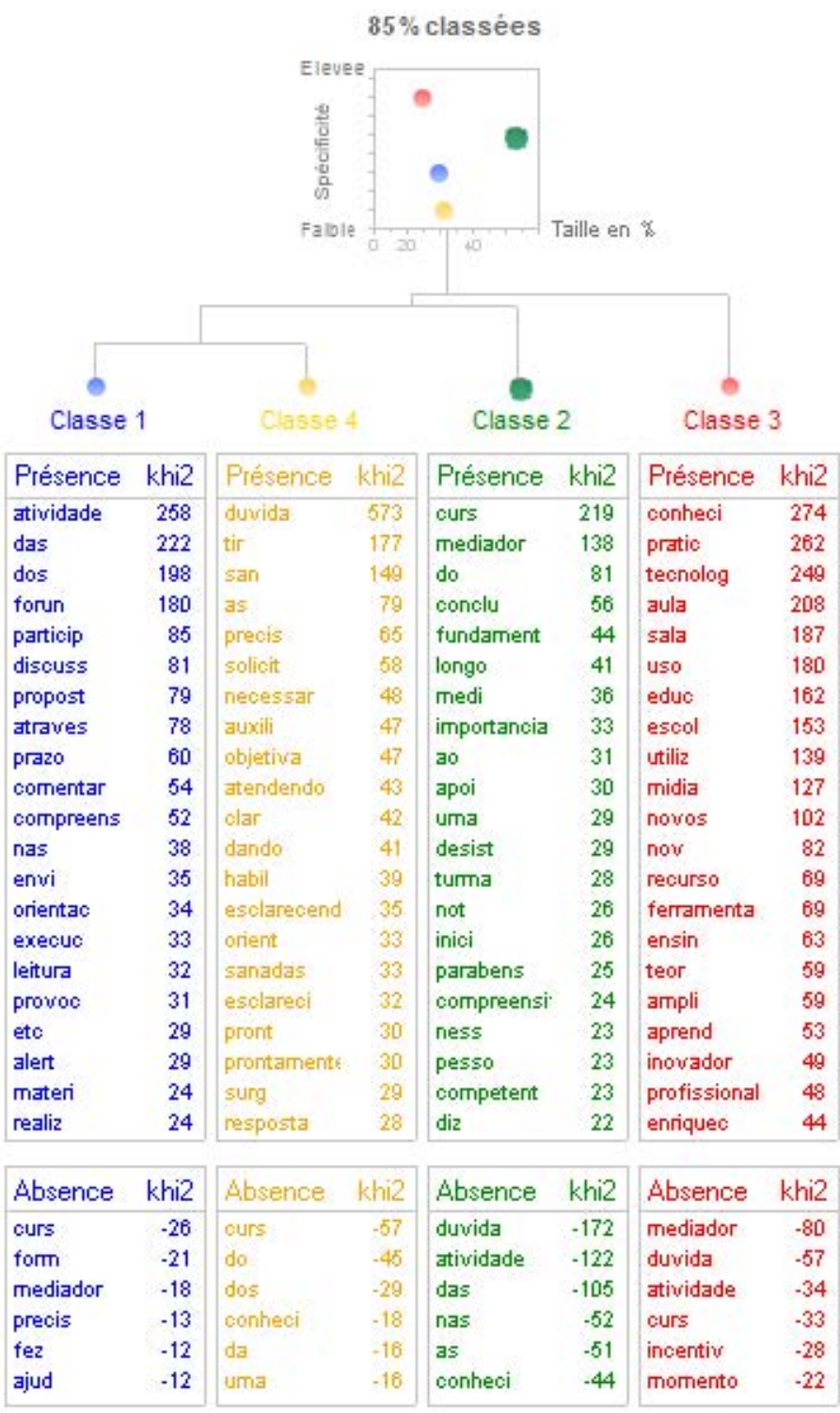

Classifinatinn douthle - nonde 121 - Mardi 15 , lanvier 2013 à 12 h 18

Fonte: Alceste 
As divisões entre as classes representam a relação de proximidade de sentidos existentes entre elas, dessa forma as classes 1 e a 4 são as que têm o sentido mais próximo. Em uma segunda análise se aproximam da classe 2 e já na terceira análise se aproximam da classe 3. Considerando as palavras e/ou as formas reduzidas que a compõem é possível nomearmos a formação de cada grupo ou classe.

Segundo Nascimento (2004), nomear as classes resultantes do software Alceste é um procedimento que envolve a análise do relatório de uma forma ampla, juntamente com os outros resultados gerados pelo programa, além de uma familiaridade com o corpus analisado. Dessa forma, as unidades de contexto elementar (UCE) foram lidas em conjunto para que fosse viável extrair um sentido geral de cada classe, sendo possível nomear a classe 2 - mediador como o principal motivador do aluno.

A Classe 2 é hierarquicamente superior a classe 1 e 4 e contém $44 \%$ das UCE analisadas. Identificamos nesta classe, UCE relacionadas ao mediador como alguém que motiva o aluno durante o curso e sobre as estratégias avaliativas usadas pelo mediador. Encontramos, também, depoimentos de cursistas que atribuíam ao mediador sua conquista por concluir o curso. Estas categorias podem ser observadas no dendograma da figura 2, assim como as associações de palavras lemas nas unidades de contexto do corpus de análise.

Figura 2. Dendograma de CHA da Classe 2

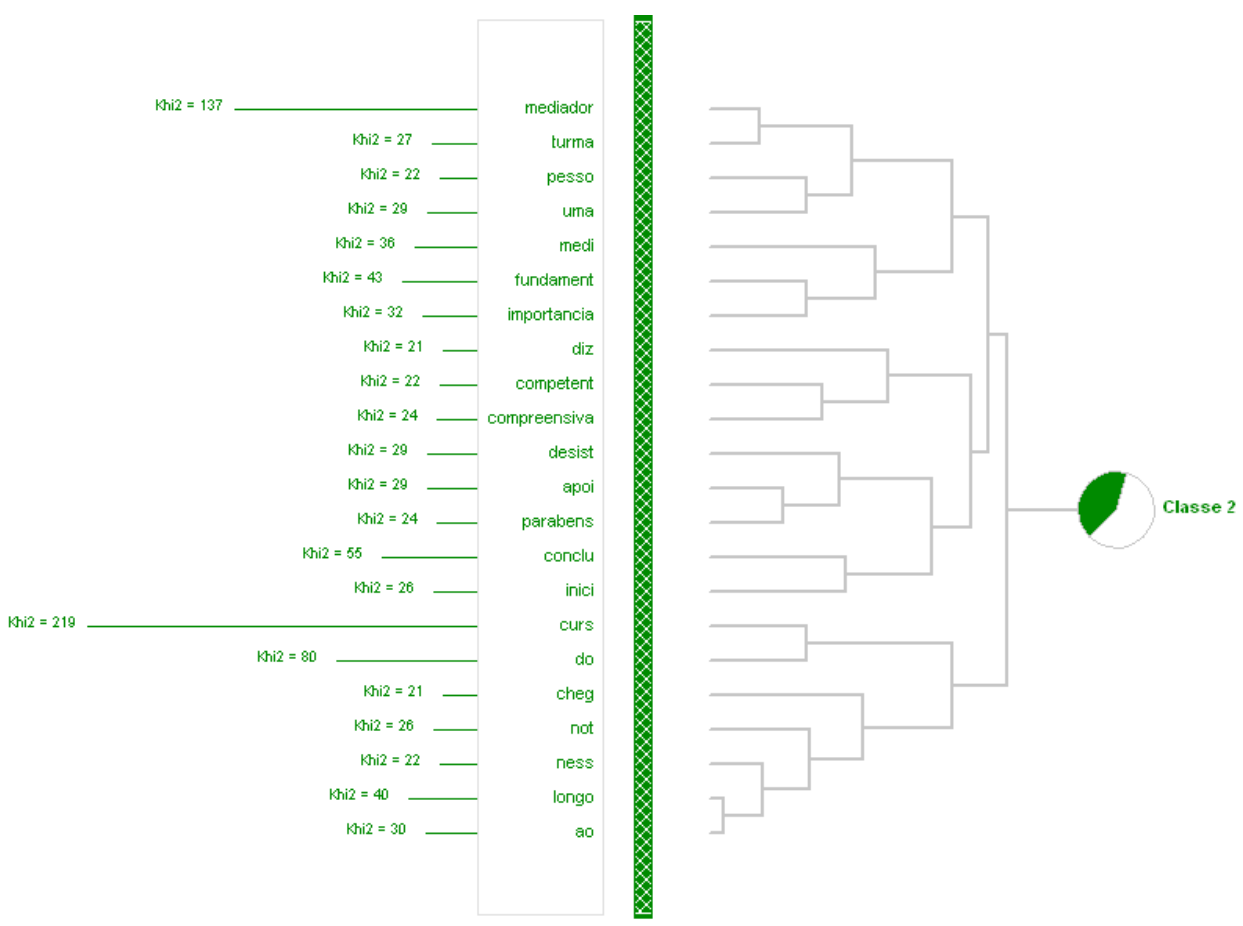

Fonte: Alceste 
Nota-se nesse dendograma uma divisão entre dois grupos maiores, sendo que no primeiro grupo ocorre outra divisão. Os sentidos presentes no primeiro grupo são: a importância do mediador para a conclusão do curso, a partir dos radicais mediador+, fundament+, importancia+; e as características ou atribuições do mediador para que possa motivar o aluno, no qual identificamos a partir dos radicais competent+, compreensiva+, desist+, parabens+; e o apoio do mediador para que o aluno concluísse a especialização, presentes nas palavras lemas desist + , apoi+ conclu+ inici+. Já no segundo grupo, percebeu-se o sentido da importância do mediador acompanhar o desempenho do cursista ao longo do curso e as estratégias utilizadas para esse acompanhamento, sendo considerado por meio da análise das palavras lemas curs+, cheg+, not+ e longo+ em suas unidades de contexto elementar.

$\mathrm{O}$ quadro da figura 3 nos auxiliar a visualizar a organização das categorias presentes na classe 2 .

Figura 3. Categoria Motivação ao Aluno

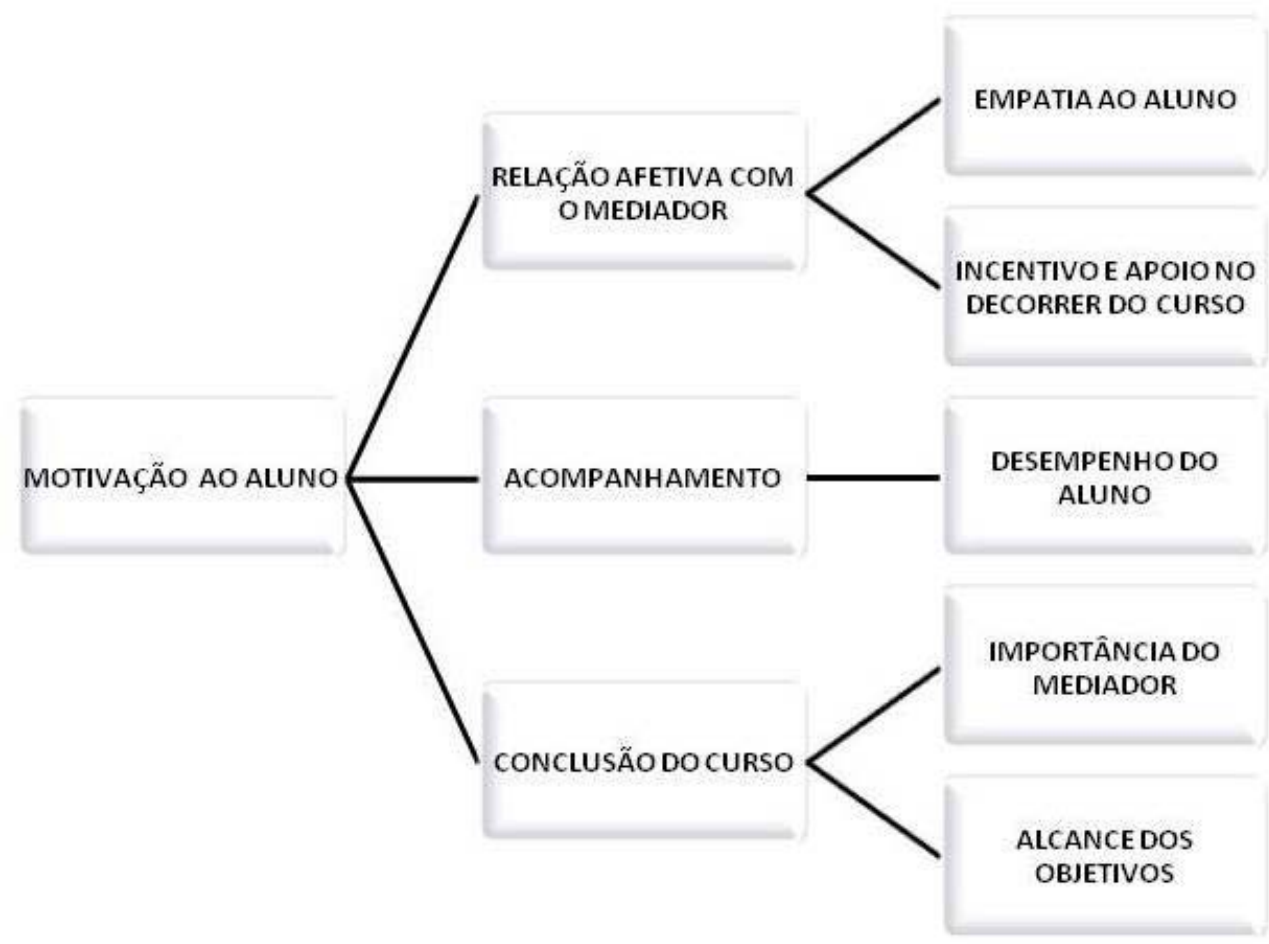

Fonte: Silva (2013) 
A figura 3 nos auxilia a verificar a Classe 2, motivação ao aluno, que possui como componentes a relação afetiva com o mediador, avaliação e conclusão do curso. Consideramos a seguir, as categorias que surgem a partir das falas dos alunos.

\section{Categoria - Relação afetiva com o mediador}

A afetividade está presente nos processos de ensino e de aprendizagem, seja na relação que se estabelece entre o aluno e seus pares, ou na relação professor-alunos e pode ser considerada como uma estratégia de motivação, visto que só é possível o aluno se sentir motivado pelo mediador se existir uma relação afetiva entre eles. Embora exista um discurso de que a afetividade construída na EaD é frágil ou inexistente em consequência do afastamento físico e temporal e do uso intensivo de tecnologias da informação, pesquisas (Campos, 2011; Campos et al., 2013) mostram que é possível construir relações afetivas com os alunos por meio ambiente virtual de aprendizagem na educação a distância.

Andrade e Vicari (2003) destacam que a afetividade e a motivação são aliadas no processo de aprendizagem, exercendo grande influência no processo de interação. Segundo as autoras, "a afetividade é considerada pelo construtivismo interacionista como a energia subjacente à ação, regulando as trocas entre o sujeito e o objeto do conhecimento" (p. 156). Da mesma forma, consideramos que uma sala de aula virtual ou o AVA precisa propiciar interfaces que garantam a promoção da afetividade entre seus participantes, assim como impulsione a motivação na relação entre seus pares e entre mediador e alunos. Vejamos como os alunos trouxeram a questão da afetividade em suas falas:

O mediador sempre esteve presente em todos os momentos, respondia e tirava as duvida existente, contribuia com suas indagações, sugestões, foi um prazer caminhar com sua pessoa que mesmo distante se fazia presente.

$$
{ }^{*} \text { Ind } \_96{ }^{*} \text { Gen_F }{ }^{*} \text { Turma_ALo3 }
$$

... minha mediadora foi fantástica. Estava sempre atenta a tudo e dando suporte inclusive emocional quando as dificuldades apareciam.

*Ind_479*Gen_F *Turma_DFo2

A mediadora foi sempre competente e amável com o grupo. Isso fez com que muitos professores prosseguissem o curso. Gostaria de ter conhecido pessoalmente para agradecer e dizer que ela e uma pessoa do bem.

*Ind_755 *Gen_F *Turma_MAo5 
...posso dizer que fui feliz com o mediador da minha turma MSo4. A forma carinhosa como ele se comunicava conosco, dava a impressão de-que não estavamos sozinhos nessa caminhada; pois so o fato do curso ser a distância, da uma ideia de estarmos sozinhos.

\section{${ }^{*}$ Ind_934 ${ }^{*}$ Gen_F ${ }^{*}$ Turma_MSO4}

A dedicação e a responsabilidade do mediador pedagógico nos estimulou o tempo todo incentivando-nos a continuar. O mediador pedagógico teve um papel importantíssimo para uma participação efetiva e na continuação no curso.

\section{*Ind_288*Gen_F *Turma_BAo1}

Os depoimentos dos alunos nos permitem perceber as relações de afeto que foram construídas com o mediador pedagógico. São relatos de como cada cursista se sentiu motivado a continuar no curso apesar dos percalços, que muitas vezes eram compartilhados com o mediador. Tais falas concordam com Vygotsky (2000) quando afirma que a motivação impulsiona necessidades, interesses, desejos e atitudes particulares no sujeito.

$\mathrm{Na}$ perspectiva histórico-cultural de Vygotsky, a afetividade é mediada pelos significados construídos em determinados contextos em que os sujeitos estão inseridos. Se tivermos como contexto o ambiente virtual de aprendizagem, podemos considerar que ao ser habitado por alunos e pelo mediador pedagógico, mesmo em situações atemporais em que não é possível que todos habitem e interajam no espaço ao mesmo tempo, ainda assim, existe a afetividade e a motivação.

A afetividade e o intelecto são uma unidade (Vygotsky, 2000; Wallon, 2007). A interação social entre os sujeitos é o que impulsiona o desenvolvimento intrapsíquico, inclusive em espaços-tempos viabilizados pela escrita e pelas tecnologias digitais enquanto mediadores culturais. A aquisição de conceitos científicos passa pela relação afetiva entre o mediador que contribuirá para a aprendizagem do aluno, ajudando-o no confronto dos conceitos espontâneos já internalizados e os novos saberes que estão sendo apresentados. A emoção está subjacente a essa dinâmica e eventualmente poderá aproximar mediador e aluno nessa construção, alimentando a motivação para conquista de novos saberes e maior vinculação ao curso.

Entre a emoção e a atividade intelectual existe a mesma evolução, mesmo antagonismo. Antes de qualquer análise, o significado de uma situação se impõe pelas atividades que desperta, pelas disposições e atitudes que suscita. No desenvolvimento psíquico, essa intuição prática precede de longe a capacidade de discriminação e de comparação. É uma primeira forma de compreensão, mas ainda totalmente dominada pelo interesse do momento e comprometida com os casos particulares. Entre indivíduos, são o acordo ou a reciprocidade das atitudes os primeiros a poder realizar uma espécie de contato e de entendimento mútuos, mas ainda totalmente absorvidos pelos apetites ou pela impulsividade do instante presente (Wallon, 2007, p. 152). 
O reconhecimento da interdependência entre afetividade, intelecto e motivação contribuem para uma mediação pedagógica empática que reconhece os sinais que podem interferir na aprendizagem, permitindo a definição de estratégias que considerem a especificidade de cada aluno, com uma atmosfera de confiança, colaboração e curiosidade investigativa.

\section{Categoria - Acompanhamento}

O acompanhamento e a avaliação de cursos na modalidade a distância tem se configurado um grande desafio, principalmente quando o que está em cheque é a qualidade do ensino. O curso de Especialização em Tecnologias em Educação adotou um processo de avaliação formativa, para tanto foi necessário montar uma estrutura de acompanhamento do aluno, onde os alunos eram avaliados pelo mediador pedagógico no decorrer do seu percurso de aprendizagem, uma autoavaliação da própria atuação no curso, e por fim participavam de avaliações institucionais, nas quais fizeram avaliações da estrutura do curso, assim como de todos os atores envolvidos, tais como coordenação, suporte técnico, material didático, professores e mediadores pedagógicos.

Roque (2011) compreende que a avaliação e o acompanhamento de alunos na modalidade a distância deve considerar o desenvolvimento da autonomia crítica dos alunos, um objetivo fundamental. Além disso, a educação a distância não conta com a presença física do mediador, sendo necessário desenvolver métodos de trabalho que propiciem a confiança do aluno, possibilitando ao cursista o processo de elaboração de seus próprios juízos e também a capacidade de analisá-los.

Segundo Campos (2002), fazer o acompanhamento e avaliar os alunos consiste em uma atividade complexa, fazendo parte das atribuições do mediador pedagógico a realização desta atividade. De acordo com a autora, o acompanhamento por parte do mediador é o método mais utilizado para efetivar a interação pedagógica, sendo de grande importância para o processo de avaliação. A atividade de acompanhar e avaliar os alunos contempla corrigir trabalhos, sugestão de ideias, dirigir e supervisionar o processo de ensino e a avaliação do aluno e do processo.

Roque (2011) percebe a interatividade como o principal elemento de acompanhamento de cursistas. No entanto, a autora considera que carecem de reflexão os aspectos que podem ser avaliados e relacionados com a interatividade e ressalta o uso do fórum, chat, lista de discussão, entre outros elementos de forma a acompanhar o aluno. Abaixo, podemos atentar sobre a importância do acompanhamento do mediador para o processo de aprendizagem dos cursistas.

...ela é fundamental para o desempenho do cursista ao longo do curso. A nossa mediadora ausentou-se na reta final, dificultando a comunicação.

$$
{ }^{*} \text { Ind_456 }{ }^{*} G e n \_F{ }^{*} T u r m a \_C E O 6
$$


...essa mediação foi de suma importância, pois ela serviu de pilar para o meu desempenho durante o curso, pois como-se trata de um curso a-distância, se não houvesse uma mediação eficaz ficaria quase impossível a conclusão do mesmo.

$$
{ }^{*} \text { Ind_36 }{ }^{*} \text { Gen_F }{ }^{*} \text { Turma_ACo4 }
$$

A mediação pedagógica foi de suma importância para o meu desempenho acadêmico. Recebi da mediadora todo o suporte possível e ainda muito incentivo para que pudesse concluir o curso TIC.

\section{${ }^{*}$ Ind $\_821{ }^{*} G e n \_F{ }^{*} T u r m a \_M G o 4$}

...minha mediadora pedagógica foi peça chave para meu desempenho neste curso com a modalidade a-distância! Achei_a ótima e alguém que sempre enfatizou e guiou as tarefas que tínhamos que realizar.

*Ind_1805*Gen_F*Turma_SCO3

A mediação pedagógica foi de extrema importância para meu desempenho no curso, tendo em vista que estamos recentemente sendo inseridos nesta modalidade de ensino a-distância, pois muitas vezes, a sensação de estar sozinho é constante.

$$
{ }^{*} \text { Ind_254*Gen_F *Turma_APo5 }
$$

A mediação pedagógica realizada ao longo do curso contribuiu para o meu desempenho acadêmico de todas as formas possíveis. Foi extremamente importante para a minha continuação no curso, com estímulos e apoio.

${ }^{*}$ Ind_780 ${ }^{*} G e n \_F * T u r m a \_M G o 1$

...mediaçao pedagógica deixou a desejar. Penso que o tutor de um curso nessa modalidade de ensino deve ser atuante, avaliar as atividades propostas e em seguida emitir um parecer.

$$
{ }^{*} \text { Ind_940 *Gen_F *Turma_MSo5 }
$$

...sempre com muita responsabilidade e compromisso a mediadora pedagógica nos acompanhou e auxiliou. considero nota 10 o trabalho dela, o-qual contribuiu sobremaneira para o desempenho que tive ao longo do curso.

$$
\text { *Ind_1252 *Gen_F *Turma_PIo5 }
$$


Podemos perceber a partir dos depoimentos, que, na concepção dos alunos, existe uma relação entre a mediação e o bom desempenho do curso, inclusive como forma de possibilitar sua finalização. Evidenciou-se também uma relação de motivação e afetividade por meio de incentivos e apoio para a realização das atividades.

Os cursistas não trouxeram claramente em suas falas se os processos avaliativos desenvolvidos pelo mediador podem ter influenciado em seu bom ou mau desempenho durante o curso. Talvez esse possa ser um indicativo da preferência dos alunos por um tipo de avaliação processual que não esteja ligado a notas e sim à sua aprendizagem, fazendo-se necessário para isso um grande comprometimento dos alunos e dos mediadores com as atividades e participação de qualidade no ambiente virtual de aprendizagem.

\section{Categoria - Conclusão do Curso}

O item conclusão do curso evidencia a importância do mediador pedagógico para a finalização do curso de cada aluno. Em suas falas, os cursistas conseguiram mostrar como o mediador os motivou para o alcance dos objetivos propostos de forma a chegarem ao final da especialização. Mais uma vez fica clara a relação afetiva que foi construída entre mediador e aluno por intermédio de depoimentos carregados de emoções e dedicação ao mediador como um dos principais atores em seu processo formativo. Vejamos as formas em que os cursistas trouxeram essas questões à tona:

Para mim foi de fundamental importancia, uma vez que só nao desisti do curso, em razão da minha mediadora não ter desistido de mim. Posso dizer que ela foi a grande responsável pela minha conclusao do curso.

\section{*Ind_233 ${ }^{*}$ Gen_F ${ }^{*}$ Turma_APo3}

A atuação da mediadora foi determinante para-que eu conseguisse concluir o curso. Ela foi uma presenca constante durante todo o curso, incentivando, motivando e valorizando a participacao do grupo.

*Ind_1845*Gen_F *Turma_SCo8

...bom a mediação pedagógica foi fundamental para a realizacao de minhas atividades como cursista, bem-como tínhamos um apoio a mais para permanecer no curso.

$$
{ }^{*} \text { Ind_16 }{ }^{*} \text { Gen_F }{ }^{*} \text { Turma_ACo2 }
$$

A mediação pedagógica foi essencial para minha continuidade no curso, por muitas vezes pensei em parar no meio do caminho, mas o acompanhamento feito 
pela mediadora, sempre demonstrava a preocupação que a mesma tinha em que chegássemos ao final com êxito.

$$
\text { *Ind_53 *Gen_F *Turma_ACo6 }
$$

...em muitos momentos a intervenção da mediadora foi fundamental pra que eu não desistisse do curso, sempre-que necessário ela mostrou onde deveríamos melhorar, acho q a participação da mediadora foi fundamental pra chegarmos ao final deste curso.

$$
\text { *Ind_674 *Gen_F *Turma_GOo5 }
$$

A dedicação e a responsabilidade do mediador pedagógico nos estimulou o tempo todo incentivando_nos a continuar. O mediador pedagógico teve um papel importantíssimo para uma participação efetiva e a continuação no curso.

$$
{ }^{*} \text { Ind_288*Gen_F }{ }^{*} \text { Turma_BAo1 }
$$

O meu mediador foi um grande incentivador para-que eu não desistisse, porque pela quantidade de tarefas executadas por mim, me faziam querer desaminar, mas ele foi muito importante, posso dizer que cheguei ao final por insistência dele.

$$
{ }^{*} \text { Ind_1815 }{ }^{*} \text { Gen_F }{ }^{*} \text { Turma_SCO4 }
$$

As falas dos cursistas nos sinalizam a importância da díade afetividadeacompanhamento para que o aluno se sinta motivado durante toda sua trajetória de aprendizagem do curso de especialização. Mais uma vez o mediador pedagógico é visto como o representante desse processo, embora saibamos que existem outros indicadores que favorecem a motivação do aluno durante o curso, como o suporte, design didático, ambiente virtual entre outros (Campos, 2011).

\section{CONSIDERAÇÕES FINAIS}

Refletir sobre a importância da afetividade nos cursos a distância é necessário se quisermos compreender melhor o processo de aprendizagem dos nossos alunos, pois a motivação dos alunos no decorrer do curso também é vista como atribuição à mediação pedagógica. Inclui-se aqui a relação afetiva que se estabelece entre mediador e cursistas, o acompanhamento do desempenho do aluno com constantes feedbacks e os incentivos para que o cursista permaneça e conclua a especialização com qualidade.

Nesse sentido, percebemos que, embora ainda seja comum a visão tradicional ou reativa da atuação do mediador pedagógico em algumas propostas de cursos, 
é preciso sinalizar que esta perspectiva vem mudando à medida que o aluno experimenta outras formas e estratégias de aprender na modalidade a distância.

Como discutido no decorrer do artigo, em suas vozes, os cursistas delegam ao mediador grande parte da responsabilidade por terem conseguido concluir o curso, ficando clara a relação afetiva construída entre mediador e aluno. Muitos cursistas relataram que em momentos de quase desistência, devido às mais diferentes dificuldades, foi o mediador que motivou o aluno, ajudando-o a continuar no curso e vencer os obstáculos que foram aparecendo durante o percurso formativo.

Esses achados são confirmados pelos estudos analisados anteriormente (Simoneto, Murgo e Ruiz, 2016; Pereira e Almeida, 2015; Goulao, 2016), e se vinculam ao conceito de trabalho investido de Tardif e Lessard (2014), quando os autores anunciam que há um envolvimento pessoal do professor com seus alunos, deixando claras as suas emoções para estabelecer os vínculos afetivos. A mediação docente então, repousaria sobre “ emoções, afetos, sobre a capacidade não só de pensar nos alunos, mas também de perceber e sentir suas emoções, seus temores, suas alegrias, seus próprios traumas, etc. O professor experiente sabe tocar o piano das emoções do grupo, provoca entusiasmo, sabe envolvê-los na tarefa, etc." (Tardif e Lessard, 2014, p. 258).

As relações afetivas entre docente e discente também colaboram para condições afetivas positivas entre o aluno e os conteúdos acadêmicos (Veras e Ferreira, 2008; Tovar e Bercht, 2016). Portanto, acreditamos que este trabalho eventualmente poderá contribuir para referirmos melhor a atuação, competência e formação de docentes para atuarem na educação a distância colocando a afetividade em pé de igualdade com a construção do conhecimento científico a partir da intervenção da mediação pedagógica.

\section{NOTAS}

1. O software Alceste - Análise dos lexemas coocorrentes num conjunto de segmentos de texto - realiza uma análise de conteúdo analisando as coocorrências frequentes de palavras dentro da mesma frase ou parágrafo. De acordo com Bauer (2008), o procedimento consiste em uma análise estatística do texto que supõe que a ocorrência de pares de palavras seja semanticamente relevante. É um software proprietário que pode ser adquirido pelo link http://www.alcestesoftware.com.br

2. Dendograma da Classificação Hierárquica Descendente mostra o resultado do cálculo estatístico que o software Alceste realiza. Segundo Kronberger e Wagner (2008), a hierarquização das classes demonstra análises sucessivas das palavras plenas, que se interrompe se um predeterminado número de repetições não resulta em divisões posteriores. A classificação hierárquica descendente só encerra quando as classes se mostram estáveis. 


\section{REFERÊNCIAS BIBLIOGRÁFICAS}

Andrade, A., e Vicari, R.(2003). Construindo um ambiente de aprendizagem a distância inspirado na concepção sociointeracionista de Vygotsky. (257273). En M.Silva (org.), Educação Online. São Paulo: Edições Loyola.

Andrade, M., Freire, J., e Neri, M. (2015). Mecanismos de afetividade no ensino a distância - relação tutor e aluno, no contexto universitário. Anais. $8^{\circ}$ Encontro Internacional de Formação de Professores e $9^{\circ}$ Fórum Permanente de Inovacão Educacional. Recuperado de https://eventos.set.edu.br/index.php/ enfope/article/view/1772

Bannel et al. (2016). Educação no século XXI: cognição, tecnologias e aprendizagens. Petrópolis, RJ: Vozes; Editora PUC.

Bauer, M. W. (2008). Análise de Conteúdo Clássica: uma revisão. En M. Bauer et al., Pesquisa Qualitativa com texto, imagem e som: um manual prático. (7 $7^{\mathrm{a}}$. ed.). (189221). Petrópolis, RJ: Vozes.

Brasil (2005). Decreto 5622, de 19 de dezembro. Recuperado de http://www. planalto.gov.br/ccivil 03/ Ato2004 2006/2005/Decreto/D5622.htm

Campos, G. (2002). Avaliação em cursos on-line. Formação e Treinamento Online. Escola Internet. Colunas. Revista TI. Recuperado de http://www.timaster. com.br/revista/colunistas/ler colunas emp.asp?.cod $=522$

• (2011). Mediação pedagógica: cooperação entre pares como estratégia pedagógica. En G. H. B. Campos et al., As relações colaborativas: desafios $d a$ docência online, (49-74). Curitiba, PR: CRV.

. (2007). Tecnologias em Educação: Uma experiência em larga escala de formação de professores para o uso de tecnologia em sala de aula. Coordenação Central de educação a Distância. Rio de Janeiro: Ed. PUC-Rio.
Campos, G. H. B., Ziviani, C., Silva, E. C., e Roque, G. O. (2013). Díade mediadoraluno: Relações de cooperação. Tecnologias, sociedade e conhecimento, 1(1), 57-79, NIED, UNICAMP. Recuperado de http://www.nied.unicamp.br/ojs index.php/tsc/article/view/110/98

Carvalho, M. R., e Lima, R. L. (2015). A Importância da afetividade na EaD: uma perspectiva de Wallon. Revista EDaPECI. São Cristóvão (SE), 15(1), 192-205. Recuperado de http://www.seer.ufs.br/ index.php/edapeci/article/view/3391

David, P. B. et al. (2014). Análise da afetividade em fóruns virtuais: construção de uma ontologia de domínio. Nuevas Ideas en Informática Educativa. (821826). Recuperado de http://www.tise. cl/volumen10/TISE2014/tise2014 submission 288.pdf

Ferreira, A. L., eAcioly-Regnier, N. M. (2010). Contribuições de Henri Wallon à relação cognição e afetividade na educacão. Educ. rev., 36, 21-31. doi: http://dx.doi. $\mathrm{brg} / 100 /$ So104-40602010000100003

Goulao, M. F. (2016). Comunicação e afetividade em ambientes virtuais. Revista EDAPECI, 16(1), 162-177. Recuperado de http://www.seer.ufs.br/index.php edapeci/article/view/4863

Kronbernger, N. et al. (2008). Palavraschave em contexto: análise estatística de textos. En M. Bauer et al., Pesquisa Qualitativa com texto, imagem e som: um manual prático. (7a. ed.). Petrópolis, RJ: Vozes.

Liew, T. W., Zin, N. A. M., Sahari, N., e Tan, S. (2016). The Effects of a Pedagogical Agent's Smiling Expression on the Learner's Emotions and Motivation in a Virtual Learning Environment. International Review of Research in Open and Distributed Learning, 17(5), 248-266. doi:http://dx.doi.org/10.19173 irrodl.v17i5.2350 
Nascimento, A. (2004). Memória dos verdes anos: saudade da infância na música popular brasileira - uma investigação e uma proposta de análise de dados. (Tese doutorado). Universidade Federal do Espírito Santo, Programa de PósGraduação em Psicologia.

Réka, J. et al. (2015). Implications of Motivational Factors Regarding the Academic Success of Full-time and Distance Learning Undergraduate Students: A Self-determination Theory Perspective. Procedia - Social and Behavioral Sciences, 187, 50-55. doi: 10.1016/j.sbspro.2015.03.010.

Roque, G. (2011). Avaliação de aprendizagem em atividade desenvolvida a distância. En G. H. B. Campos et al., As relações colaborativas: desafios da docência online. (75-100). Curitiba, PR: CRV.

Silva, E. C. (2013). Concepção dos alunos sobre mediação pedagógica: um estudo de caso em curso na modalidade a distância. Dissertação de Mestrado não publicada, Departamento de Educação, Pontifícia Universidade Católica do Rio de Janeiro, Rio de Janeiro, Brasil.

Simonetto, K., Murgo, C., e Ruiz, A. (2016). Afetividade Na Educação: A Distância Sob O Olhar De Alunos De Pós-Graduação. Rev. FSA, Teresina, 13(1), 83-96. doi: http://dx.doi.org/10.12819/2016.13.1.5
Tassoni, E. C. M., e Leite, S. A. S. (2013). Afetividade no processo de ensino e aprendizagem: as contribuições da teoria walloniana. Educação, 36(2), 262-271, Recuperado de http://revistaseletronicas. pucrs.br/ojs/index.php/faced/article/ download/9584/9457

Tardif, M., e Lessard, C. (2014). O Trabalho docente - Elementos para uma teoria da docência como profissão de interações humanas. ( $9^{\mathrm{a}}$ edição). Petrópolis: Vozes.

Tovar, E. F., e Bercht, T. (2016). Explorando la dimensión afectiva entre el estudiante y el conocimiento matemático mediado por las TIC. Novas Tecnologias na Educacão, 14(1) 1-9. Recuperado de http://seer. ufrgs.br/index.php/renote/article/ view/67381/38472

Veras, R. S., e Ferreira, S. P. A. (2010). A afetividade na relação professor-aluno e suas implicações na aprendizagem, em contexto universitário. Educ. rev., 38(1), 219-235. Recuperado de http://www.scielo.br/scielo. php? script =sci arttext\&pid $=$ So104 40602010000300015\&lng=en\&nrm=iso

Vygotsky, L. (2000). A Formação Social da Mente. São Paulo: Martins Fontes.

Wallon, H. (2007). A evolução psicológica da criança. São Paulo: Martins Fontes.

\section{PERFIL ACADÊMICO E PROFISSIONAL DAS AUTORAS}

Eunice de Castro e Silva. Pedagoga e Especialista em Educação com Aplicação da Informática pela Universidade do Estado do Rio de Janeiro e Mestra em Educação pela Pontifícia Universidade Católica do Rio de Janeiro, onde atualmente cursa o Doutorado em Educação. Pedagoga da Universidade Federal Fluminense e coordenadora da disciplina de Didática no consórcio UENF/CEDERJ. Integrante do grupo de pesquisa Cooperação e Avaliação em Educação a Distância/ PUC-Rio/ CNPQ.

E-mail: nicepeda@gmail.com 


\section{ENDEREÇO DA AUTORA}

Rua Miguel de Frias, 9

Icaraí, Niterói - RJ.

Cep 24220-900

Keite Melo da Silva. Pedagoga pela Universidade do Estado do Rio de Janeiro, especialista em Mediação Pedagógica em Educação a Distância pela Pontifícia Universidade Católica do Rio de Janeiro (PUC-Rio) e Mestra em Educação pela Universidade Estácio de Sá. Está cursando o Doutorado em Educação pela PUC-Rio. Professora do curso de Pedagogia do Instituto Superior de Educação do Rio de Janeiro e Orientadora de Trabalhos de Conclusão de Curso (TCC) pela Universidade Federal Fluminense (Lante/UFF) no curso de Planejamento, Implementação e Gestão da Educação a Distância. Está licenciada para estudos pela Secretaria Municipal de Educação de Duque de Caxias. É pesquisadora do grupo de pesquisa Formação de Professores e Tecnologias Educacionais/FAETEC/CNPq e integrante do grupo de pesquisa Cooperação e Avaliacão em Educação a distância/PUC-Rio/CNPq.

E-mail: keitemelo@gmail.com

\section{ENDEREÇO DA AUTORA}

Rua Mariz e Barros, 273

Praça da Bandeira,

Rio de Janeiro - RJ, Brasil

CEP: 20270-001

Gilda Helena Bernardino Campos. Possui Licenciatura em Francês pela Pontifícia Universidade Católica do Rio de Janeiro, Graduação em Pedagogia pela Pontifícia Universidade Católica do Rio de Janeiro, Mestrado em Educação pela Universidade Federal do Rio de Janeiro e Doutorado em Engenharia de Produção pela COPPE -Universidade Federal do Rio de Janeiro. Atualmente atua como Coordenadora Central de Educação a Distância da Pontifícia Universidade Católica do Rio de Janeiro e como Profa. do Departamento de Educação da PUC-Rio. Tem experiência na área de Educação, com ênfase em Tecnologias Digitais da Informação e Comunicação aplicadas a Educação, atuando principalmente nos seguintes temas: educação a distância, informática na educação, ambientes de aprendizagem mediados por tecnologias, avaliação da qualidade de produtos educacionais e avaliação da aprendizagem. É Coordenadora do grupo de Pesquisa "Cooperação e avaliação em Educação a Distância. 


\section{ENDEREÇO DA AUTORA}

Ed. Padre Leonel Franca,

$2^{\circ}$ andar. Rua Marquês de São Vicente, 225

Gávea, Rio de Janeiro - RJ - Brasil.

CEP 22453-900

Data de recebimento do artigo: 13/10/2016

Data de aceite do artigo: 07/12/2016

\section{Como citar este artigo:}

Castro, E., Melo, K. S., e Campos, G. H. B. (2018). Afetividade e motivação na docência online: um estudo de caso. RIED. Revista Iberoamericana de Educación a Distancia, 21(1), pp. 281-301. doi: http://dx.doi.org/10.5944/ried.21.1.17415 